\title{
BLOG MARKETING - A RELEVENT INSTRUMENT OF THE MARKETING POLICY
}

\author{
Stremțan Filimon ${ }^{1}$ \\ Achim Moise Ioan ${ }^{2}$ \\ Radu Lucian Alexandru ${ }^{3}$ \\ Radoviciu Ruxandra ${ }^{4}$
}

\begin{abstract}
The number of internet users is continuously expanding, and the number of people with a personal blog is rising in a vertiginous rate from one year to the next. In this context, the Blog Marketing is starting to play an important part within the marketing strategies of companies/organizations/persons. Different aspects of the personal blog are becoming defining elements of the image we are trying to project in the blogosphere. Promotion through the World Wide Web and advertising through the blog are becoming essential elements of the development and attraction of the potential clients' interest for products and services offers by a firm, by a non-profit organization or by a person.
\end{abstract}

Key words: blog, marketing, promotion, advertising

JEL Codes: M30, M31

\section{State of the Internet}

According to www.internetworldstats.com, the number of internet users has grown from 360.985 .492 users in the year 2000 to 1.596 .270 .108 users (23.8\% of the global population) in 2008 $-\mathrm{a}$ rise of $342.2 \%$.

As a percentage from the population with access to the internet, the areas with the largest coverage are North America - with 74.4\% (251.290.489 users), Oceania/Australia with 60.4\% (20.783.419 users) and Europe with 48.9\% (393.373.398 users), followed by Latin America with 29.9\% (173.619.140 users), the Middle East with 23.3\% (45.861.346 users), Asia - 17.4\% (657.170.816 users) and Africa with 5.6\% (54.171.500 users).

Thus, in the present framework of the fast development of communications and information transfers through the internet, the web marketing plays a growing role in the marketing policy of private investors, of companies and non-profit organizations.

The blog marketing has an important role in the context of the current web evolution within this type of marketing.

\section{Blog characteristics}

The blog is a "web log", meaning a web site with the following features:

- the entries are directed towards one or more subjects, illustrative of the expertise area or of the concerns of the person who is posting the blog;

\footnotetext{
${ }^{1}$ Management - Marketing Department, “1 Decembrie 1918” University of Alba Iulia, 11-13, N. Iorga Street, Alba, filimon stremtan@yahoo.com;

${ }^{2}$ Management - Marketing Department, “1 Decembrie 1918” University of Alba Iulia, 11-13, N. Iorga Street, Alba, iachim@uab.ro;

${ }^{3}$ Economist, radu.lucian@ personal.ro

${ }^{4}$ Management - Marketing Department, "1 Decembrie 1918” University of Alba Iulia, 11-13, N. Iorga Street, Alba, ruxandra rdvc@yahoo.com;
} 
- the blog is usually kept up by one person;

- is easy to update, therefore the entries' frequency is pretty high (usually at least twice a week);

- the entries are arranged chronologically backwards (thus, the newest is always the first on the page);

- most blogs allow the readers to post comments right below the published article;

- communication is direct, less formal and subjective.

Unlike the regular sites, which are more static, updated less frequently and tend to be more impersonal and less provoking for communication, the blogs are based on tools that post the articles almost instantaneous, they have a very dynamic content, are easy to update and have a more personal appearance and lure you to post comments and to communicate.

\section{State of the Blogosphere}

According to "Technorati's State of the Blogosphere 2008 report", Technorati has added 133 million blogs (starting from the year 2002). Within the blogopshere there are approximately one million posts published a day.

In 2004 when Technorati started, the typical reaction to the word 'blog' was 'huh - can you repeat yourself?' Today, blogs are everywhere - even presidential candidates have blogs. The blog has forever changed the way publishing works - now anyone can be a publisher. The issue is no longer distribution; rather, it's relevance. - Brad Feld (Managing Director at Foundry Group). Almost all blogs are in "Top 10 web site lists - across all key categories".

Four in five bloggers post brand or product reviews, with $37 \%$ posting them frequently. $90 \%$ of bloggers say they post about the brands, music, movies and books that they love (or hate). One-third of bloggers have been approached by companies to be brand advocates.

When it comes to the demographics, the blog posters are male (with an average of 60 and $75 \%$, depending on the geographical area), college graduates (approximately $70 \%$ ), with ages relatively in the same range (between 18 and 35 and over 35 years old), except Asian Bloggers, for whom the percentage of users under 35 years old is $73 \%$.

$77 \%$ of active Internet users read blogs. Regarding their interest in the blogosphere, Gilad Mishne Maarten de Rijke (Informatics Institute, University of Amsterdam) writes in "A Study of Blog Search":

Our results show that blog searches have different intents than general web searches, suggesting that the primary targets of blog searchers are tracking references to named entities, and locating blogs by theme.

In terms of interest areas, blog searchers are, on average, more engaged in technology, entertainment, and politics than web searchers, with a particular interest in current events. The user behaviour observed is similar to that in general web search: short sessions with an interest in the first few results only.

\section{Types of blogs}

According to the study conducted by Technorati, the blogs can be divided in three large categories, depending on their subject:

- personal - where subjects of personal interest are debated (approximately $80 \%$ of all blogs are included here);

- occupational - centred upon subjects relating to a profession and to professional training, but without being written from the stand of an official spokesman of a company (many times the occupational and personal blogs are mixed when it comes to the chosen subject);

- corporate - blogs officially maintained and supported by the company the blogger is a part of (approximately 12\% of bloggers blog in an official capacity for their company).

These blogs are used to send relevant information about the company, about its employees, about the products/services it promotes/sells; they are used to upload news about new products or 
products that will be launched soon, as well as hiring and collaboration opportunities or other information useful for the readers regarding the various aspects of the client - company relationship.

They can be extremely useful for improving the company's image, with the help of the human faces who upload blogs relating directly to the company.

Max Lee talks about three types of blogs:

- Original Content Oriented Blogging - centred upon original posts, usually a niche area, relatively specialized, which require a high level of training, expertise and experience.

- Link Content Oriented Blogging - includes posts with an original content, but they refer to other posts published on other blogs/sites about that particular subject (it can be about technology, music, movies, etc). The most successful blogs in the world use this publishing technique, it helps their readers find more information in a single place, information which they can look into as they desire by following the links supplied in the post.

"In short", says Max Lee, "this is where the money is: blogs that provide one location for the reader to find all the other links out there on the internet while providing useful tips and reviews".

- Splogs - blogs that don't have an original content, which "the blogger uses automated rss fetching software to do auto blog posts".

Depending on the areas of interest approached on blogs, we can talk about:

- social and socialization blogs (centred upon various hobbies, passions, philosophical or religious orientations, etc.) - which gather an online community (more or less official) people with similar concerns and interests;

- political blogs - used for political campaigns or for political analyses. Today is a common practice for present or former dignitaries of the state or members of political parties to post regularly on their personal blogs.

- news/journalistic blogs - have a direct connection with the online editions of newspapers, magazines or the web pages of televisions or radios (where the journalists of that paper/television/radio post) or are independently created by independent journalists or other people interested in this area.

- commercial blogs - maintained by various persons or companies with the purpose to sell their products or services (for example, in tourism, or services of other nature), these blogs are kept starting with people who have a few CDs, e-books or books to sell, all the way up to big companies. - PR/client support blogs - which mediate the relationship with the clients of a company and offer support and assistance for the commercialized/sold products and services.

- etc.

\section{The two faces of the blog marketing}

When we refer to the relation between blogs and marketing, we must talk about two complementary aspects, which are closely related:

1. - the role of blog/blogs in the marketing policy promoted by the company (the blog is seen here as being an instrument used to promote the products/services of a company/organization);

2. - the role of the marketing in promoting blogs (the blog is seen here as a product that must be promoted through different marketing tools).

Regarding the first aspect (the blog's use as a marketing tool), the blogs kept by a company, person or organization (political, religious, etc.) can achieve:

- a presentation of the products and services promoted by the company and/or of the ideas and goals (political, religious) pursued by a person or a group of people - in the case of the blog, their presentation can be more personal, less formal and more direct than it is possible through other media channels (television, newspapers, magazine, etc);

- an easier, faster and less expensive way to monitor the clients' reactions to the launched products or to the company's performance (this is done by tracing and analyzing the number of visits for a 
certain post and by analyzing the number and nature of the comments on a certain subject left by the visitor);

- elucidation of the misunderstandings that can appear about the promoted products and services, or about the various aspects relating to quality, price, distribution manner, granted warranties, etc.;

- an efficient PR activity: by launching information, press releases and news through blogs about different projects of the organization.

Marketing through blogs has a few essential features which recommend it as an optimum marketing mean:

- is relatively easy to achieve - with the existent technologies supplied by companies like WordPress or Blogger, the time needed to create a blog that is ready to host the first post is $5-10$ minutes.

- implies a lower cost than the marketing conducted through other media channels, and it also implies a more rigorous control of the cost-income ratio (through the analysis tools of the visitors' activity on the blog), as well as low maintenance costs;

- offers an immediate global coverage (mediated by the Internet); a 24/7 access and an almost instantaneous communication with the visitors, through comments, responses or online chats available on the blog;

- gives an easy control of the feedback from other blogs/sites with which there are or there are no affiliation/collaboration connections, and from the advertising banners posted on other blogs or sites with the purpose to increase traffic for our own blog.

Regarding the second mentioned aspect, is obvious that blogs need a coherent marketing policy in order to benefit from a busy traffic and afterwards to generate the wanted incomes or results.

\section{The blog's appeal}

The good, original and relevant content for the readers is essential for the blog's appeal, which is achieved through:

- regular, scheduled and frequent posts (the blogs from Technorati Top 100 have an average of 10 post a day);

- posts about news from the targeted area;

- posts written as a "How to..." type of article - which explain in detail the stages that must be covered in order to successfully run a specific activity that is of interest for the reader - for example, the steps needed to place a certain web widget in a blog, accompanied by relevant images and detailed descriptions of these steps;

- a definition-presentation / technical depiction type of article for a certain aspect (an explanation given in terms specific for that area of expertise, but in a manner that is sufficiently mundane to be understood by a reader with minimum knowledge about that area);

- articles - dispute/debate - about hot, acute topics, which are of major interest at a given moment;

- articles that approach a list, a top - such as "10 ways to...", "7 advantages of...", "The best 8 methods to ...".

Regarding the content of the blog, it is recommended to avoid plagiary, to develop original and interesting opinions, written with a relevant and not boring argumentation.

\section{Promotion strategies for blogs}

The promotion of a blog can be done through methods such as:

- posting comments on other blogs relevant for the topic of your own blog - it is recommended to make them to the point, to be respectful, interesting, coherent and accompanied by a link to the blog of the person who is making the comment;

- by optimizing the blog's content in order to have a better position in the results given by search engines when certain key words are looked for - an important role is played here by the blog's title, 
its web address and its subtitle (the abstract of the targeted area, written in a sentence or a phrase), as well as the title of the uploded posts - it's important they include relevant key words for the blog's content and for the key words that the blogger is aiming at (recommended as being the most looked for by Internet users for the area the post is about). Placing adequate tags for each post and the link exchange with other blogs play an important role in this process of optimization - taking into consideration the major role that search engines grant to the number of links made for a certain blog/post in assessing the rank of that certain blog.

- creating links for posts on other blogs, hoping to get mutual recognition;

- promoting the blog on socialization networks, such as: Facebook, My Space, Twitter, etc.;

- promoting it with the help of short videos (exciting, interesting, fun) posted on YouTube, Google Video or other sites of video hosting;

- carefully monitoring and studying the traffic generated by the blog - by using specialized tools, such as Google Analytics, StatCounter, SiteMeter, Histats, etc., which show us the url of origin (the web page where the visitor came from), his ip (and thus, the location and country of origin), the type of the used browser, the visited web pages, the time spent on each of them (which shows us the post of major interest from his own blog), the time and date of the visit, the word looked for on the search engine, which led to the blog (this indicates the major areas of interest and the relevant key words that can be used for future postings about subjects often searched by Internet users (in general or at certain periods around holidays or annual events));

- creating and distributing for free e-books, e-courses, reports, case studies and papers (of 3 to 15 pages, or even 30 to 50 pages), which detail aspects of the main expertise area that the blog focuses on, and includes links for the promoted blog (for example, placed instead of the letterhead - thus appearing on every page) and invites in an explicit manner the reader to access the targeted blog for more details about that respective subject. Creating these e-books requires less sustained work, but generates a consistent traffic if their content is attractive, interesting, useful and well presented.

- adding the blog's address on business cards, or as a closing phrase in each sent e-mail - for example: "please visit my blog also:..."

- entering RSS (abbreviation for Really Simple Syndication) feeds to make it easier for those who want to follow the posts of a blogger without accessing it directly, but through these feeds hosted by sites that centralize them (for example: IGoogle, FeedBlitz, Feedburner, etc.), which can have settings for a simultaneous entry on a web page of the last posts from all the blogs added by the user in the feed he uses.

\section{Advertising on Blogs}

In the personal - occupational sphere, the blog is similar to newspapers and magazines, because most incomes generated by personal blogs come mainly from the hosted advertisements.

A few of the advertising methods promoted by blogs that can be mentioned are:

- Hosting advertising banners for a limited number of companies. With the help of web traffic tracking instruments the efficiency of certain banners can be traced in real time, and if they don't generate enough traffic, they can be replaced with more appealing banners. According to Bob Stone (Stone et Jacobs, 2004), the requirements for an efficient banner are: to be simple, to show images with people, to have a clear language, which must impel to immediate action, suggesting an urgency feeling to act by following the link it sends to.

- Using advertising networks like Google Adsense or Amazon, which in the framework given by the blogger post commercials aimed at products relating to the content of the article. An important role in maximizing their efficiency is played by the banners' position and visibility (the most recommended spots are above the post and right after it).

- Creating a data base with the e-mails of the blogs' visitors in exchange to free access to certain offers (for example, free e-books), which are then used to send advertisements included in the blog posts like reviews/presentations. In this particular case is important to have easy options to opt-in 
and opt-out, so the subscriber won't be stressed with unwanted articles.

Types of payments for the advertising services provided by blogs:

- the payment of a fixed annual or monthly sum of money, depending on the number of visitors generated by the blog (and who are thus exposed to the commercial it hosts), as well as depending on the size of the banner, its position on the blog and its visibility (given by colours, animation, size, or other features);

- the "pay per click" payment - the blogger is paid only when a visitor clicks the advertising banner and goes to its associated site - for this type of payment, he is paid a frugal sum for each visit generated for the target site (no matter whether the visitor does or does not do a commercial transaction after he started from the advertising blog).

- the "pay per transaction" payment - the one who advertises is paid only if the targeted site records a transaction as a result of the visit it generated - the payment is usually a quota from the profit of that transaction;

- the "pay per post" payment - the blogger posts presentation articles / favourable reviews of articles or specific products and receives a fixed or negotiated sum of money for each presentation / review he makes.

The companies can use the advertising space offered by successful blogs to generate traffic for their own web pages and blogs, therefore generating sales and incomes. The blog marketing can be a natural addition to the marketing mix it runs through various media channels to promote and sell its own products and services.

\section{Conclusion}

In the current time of the global communication achieved through the Internet, the blog marketing is an essential marketing instrument because of its specific characteristics.

Because is suited in the personal, occupational and corporate spheres, the blog eases communication and acts as an active factor that creates and promotes an identity specific to the virtual space of the World Wide Web, with direct and immediate implications over the materialfinancial aspects of the economic and social realities.

\section{References}

1. Yaro Starak, Blog Profit Blueprint, e-book from BlogMastermind.com.

2. David Meerman Scott, 2008. The New Rules of Marketing and PR, Published by John Wiley \& Sons, Inc., Hoboken, New Jersey.

3. David Meerman Scott, The New Rules of Viral Marketing - How word-of-mouse spreads your ideas for free, e-book from www.davidmeermanscott.com.

4. Jeremy Wright, 2006. Blog Marketing, ed. McGraw-Hill, New York.

5. Colin McKay, 2005. Incorporating Blogs in to the Marketing Mix, e-book from www.canuckflack.com (http://canuckflack.com/archives/IncorporatingBlogsHQ.pdf).

6. Max Lee, Blog Internet Marketing 101 (The E-book for Intermediate/Expert Bloggers), from www.zedomax.biz (http://zedomax.biz/ebook/internetmarketing101.pdf).

7. Stone, B., Jacobs, R., 2008. Succesfull Methods in direct marketing, Ed. ARC, Chişinău, 2004.

8. Internet World Stats, www.internetworldstats.com.

9. Technorati's State of the Blogosphere 2008 report, www.Technorati.com,2008 (http://technorati.com/blogging/state-of-the-blogosphere).

10. www.emarketer.com. 